\title{
A study on the relationship between task, information, and individual performance
}

\author{
Sinan Cayir ${ }^{\text {a }}$, Nuri Basoglu ${ }^{\text {b }}$, Tugrul U. Daim ${ }^{\text {c, * }}$ \\ a Istanbul Technical Univ, Turkey \\ ${ }^{\mathrm{b}}$ Izmir Inst of Tech, Turkey \\ ${ }^{\mathrm{c}}$ Portland State Univ, USA
}

\section{A R T I C L E I N F O}

Article history:

Received 3 September 2015

Received in revised form 29 December 2015

Accepted 3 February 2016

Available online 16 April 2016

\begin{abstract}
A B S T R A C T
The goal of this study was to find an abstract model that would address the relationship between information and task and thus lead to better business performance. The relationships among information, task, and performance are analyzed in the natural environment against job-related beliefs and technology. The final instrument was applied to professionals mainly from the Finance and Information and Communication Technology (ICT) sectors. Statistical analyses were used to quantify the relationships. The goal of the study was also to develop a model of task information fit (TIF). Results indicate that the tool has been successful and models the underlying structure between system characteristics, task characteristics, information characteristics, and their impact on perceived business success to some degree. A reduced TIF model was targeted to discover the relation between task characteristics, information characteristics, and their effect on business performance on a per-item basis. The correlations between the items supported the proposed relations.
\end{abstract}

๑) 2016 Elsevier Ltd. All rights reserved.

\section{Introduction}

21st century is characterized by its digital nature. Therefore exploring relationships that helps us to comprehend how technology impacts business and commerce are critical for technology and society studies.

In the world of information technologies, the question of finding the best solution for particular business needs has been an ongoing debate for decades, a debate that evolves with the development of technology. The effects of this spiral extend to the socialorganizational attitudes of people, raising new questions and requirements.

Those thoughts led to the following questions.

- Is it possible to develop a model that favors Information System (IS) development and is independent from technology?

- What are the main factors in IS development? Information, system ... What else?

- How about interoperability between different ISs? Why do we need interoperability?

\footnotetext{
* Corresponding author.

E-mail address: tugrul.u.daim@pdx.edu (T.U. Daim).
}

Those questions started a chain reaction of other questions that led to the creation of the Task Information Fit model. Therefore the main goal of this study was to find an abstract model that would address the relationship between information and task, thus leading to better business performance. The goal of the model is to eliminate the effect of time and technology.

The characteristics of information, task, and system are covered in the literature review. The relationship between task and information is explored. The concepts of integration and interoperability are studied. Finally, the effect of user acceptance on the use information technologies is discussed.

In the framework proposed; general system properties, task characteristics, information characteristics, beliefs of self and work, and their effect to perceived business success were examined.

The paper is composed of four additional sections. Section 2 introduces the literature review on information characteristics, task characteristics, technology acceptance, and information systems characteristics. Section 3 introduces the research methodologies and different phases of this research. In section 4, research frameworks of Task Information Fit are presented. The findings of the study are discussed in section 5 . 


\section{Literature survey}

\subsection{Work environment basic characteristics}

Work in general can be defined as a mental or physical activity or set of activities introduced to produce or accomplish something. In the work environment, it can be defined as those activities necessary to accomplish a given set of job objective(s). These activities can be mental or physical; they can be performed by human or by machines and/or computers.

\subsection{Job and job design}

Jobs can be defined as the aggregation of activities across time for a particular individual. Proper job design for the organization is highly important as it has an effect on the structures of other jobs, it stimulates interactions between peers, and it divides responsibilities among workers. It dictates the hiring policy of the human resources department as well as the training and education schemes. Most interesting for us is that it is also used to indicate how an information system should be designed. In general, division of work can be done using different criteria such as functional decoupling, load sharing, worker competency, or allocation for problem solving. Whichever design is used, it is important to develop a coordinated and coherent structure in itself in pursuit of job requirements.

The objective of job design is to generate deliberate specification of the job holders' responsibilities. The process of job design has defined as “... specification of the contents, methods, and relationships, of jobs in order to satisfy technological and organizational requirements as well as the social and personal requirements of the job holder" [2].

From the business perspective job design is expected to design the whole organizational structure to address the transformation processes from inputs to outputs and generation or revenue. Job design deals with work organization such as adding tasks, job structuring as giving control over work, and job scheduling and location.

Some of the significant job characteristics from the workers' perspective include variety, career development implications, autonomy, social significance, intrinsic motivation, collaboration opportunities, recognition, feedback, and responsibility $[2,6,7,17-19,22]$. The aforementioned characteristics are important for motivating people. These are the points to be accounted for in good job design for higher job satisfaction leading to better achievement of business objectives.

A good job design at the individual level should consider the following criteria:

- Optimal variety based on job requirements and people skills

- Being and feeling part of a whole

- A work cycle optimized for workers' needs

- Control over results and feedback

- Utilization of workers' skills, knowledge, and effort

- Perceivable contribution to the end product and recognition

Garg and Rastogi [15] built a model on Hackman and Oldham's proposal [17] on motivational factors of skill variety, task identity, task significance, autonomy, and feedback. The study added factors such as human resource management, ergonomics, organizational culture, leadership style, human performance improvement, and workplace spirituality. All the factors emphasize the workplace's role in employee motivation. The model proposed for job design takes into account external and internal organizational factors, individual values, group-level and social-level factors. All of these combined result in employee motivation and a high-performance environment. The overall system facilitates higher productivity for the organization.

The primary rationale of survival for productive corporations is continuous creation of value. Creating value relies on information processing, which is in the hands of knowledge workers. Creating a motivating job design for knowledge workers is targeting processes to foster innovation for the company. An innovation motivation antecedents model is an effort to cover that aspect [1]. The model relies on five motivating drivers: sociological, psychological, generational, work, and cultural. Management is expected to analyze the right drivers for the motivation of their knowledge workers, and then apply those drivers as antecedents in creating the target environment. Findings indicate that the job done is the primary source of motivation, followed by intrinsic and extrinsic job outcomes [1]. The last point of motivation is the organizational system, considering corporate culture, rules, procedures, work environment, etc. The concepts of autonomy, intrinsic motivation, task identity, task significance, feedback were used in the design of the task-based and self-motivation-based constructs for the present study.

\subsection{Task characteristics}

As mentioned above, one basic construct we explored in this study was task. In general, task can be defined as an activity or set of activities complete within itself or forming a part of a process. There may be or may not be roles related to a task. Usually, the task takes some input resources and produces some output products or semi-products. For an information or knowledge worker, the input is usually information provided from a system and the output is a decision given or knowledge processed to be deployed.

In a usual controlled decision, the involved information processes include activation, observation, identification, interpretation, evaluation, definition of $\operatorname{task}(\mathrm{s})$, formulation of procedure(s), and finally execution of that procedure [27]. Though the steps should be sequential, the pieces of generated information after each process can use information from previous steps. In an earlier study [27], the role of designer, operator, and computer are questioned. The designer faces most of the difficulties by designing identification, interpretation, evaluation, task definition, and formulation of procedure. The operator is asked whether to execute the formulized procedure. This is the case of a well-defined problem. The context and interaction between actors can be completely different in a case where the problem is not so well defined. In those cases, the designed system should refer much more often to the operator to ask for decisions and directions.

Another study concentrated on derivation of taxonomy for cognitive work analysis [26]. The authors described socio-technical systems as self-organizing and adaptive to the current dynamic environment. In a complex work context such as the interactions between large information systems and their users (i.e., agents), there exist multiple layers of representation for relating the cognitive and emotional characteristics of a user to his other work environment: user's resources, criteria, and values; possible user strategies, tasks in decision terms, tasks in situation domains, the means-ends structure of the work domain, the work system environment, and the information system itself. The study [26] covered subjects from multiple disciplines: domain expertise, work psychology, decision theory, work sociology, psychology, organization and management, information science.

Task can also be defined as the smallest controllable work unit performed by an employee or group of employees from different departments [31]. Job design requires functional decomposition of the job into tasks. For higher quality achievements, the 
management should include a control capacity in the individual tasks. The work structure design can be broken into job designs. A good work design improves efficiency and effectiveness. A usual task control cycle consists of four basic functions: perception of state, evaluation per aspect, integrated evaluation of all related aspects, and choosing the control activity to be performed. Establishing the task as the basic unit of business control gives us the cue to design information systems to assert business control methods at that level. The information provided at the task level could be used in decision-making processes at more integral levels of the business.

Another discussion in the job design arena is to decide between parallel, serial, or some semi-structured designs. In most of the Integral Organizational Renewal (IOR) projects, corporations introduce parallel business process decomposition in order to overcome the current business challenges [31]. On the contrary, it can be argued that parallel work design may degrade the overall performance by the introduction of increased process variability and extra coordination efforts [33].

\subsection{Task environment for knowledge workers}

Knowledge workers form most of the working class in contemporary society. Their job tasks heavily rely on information and they use information systems to complete them.

Jonassen [20] summarized problem-solving activities and categorized them as logical, algorithmic, story, rule-using, decision making, trouble-shooting, diagnosis-solution, strategic performance, case analysis, design problems, and dilemmas. These categories can be applied to differentiating between tasks as well. Task complexity was analyzed and related to several factors in the prior literature [5]. Task complexity depends on task attributes such as path multiplicity, goal multiplicity, interrelated subtasks, and uncertainty of the interaction between different paths; goals result in increased information load, diversified by type and source and changing rapidly [5].

In order to perform a task, make a decision, or solve a problem, one needs to collect the essential input information. The information required can be problem identification information, domain information, and problem-solving information [4]. Bystrom and Jarvelin [4] analyzed the relationship between task complexity, necessary information types, information channels, and sources on the task level. The findings included a positive relation with task complexity, amount of information, and sources of information. As task complexity increases, the need for domain and problemsolving information increases and the number of sources increase. Fidel et al. [14] studied on collaborative information retrieval. They defined task analysis in decision-making terms and in terms of strategies as characteristics of cognitive work. Both of the properties require some sort of information to be completed. The case study revealed that the nature of information sources and nature of information needed had an impact on collaboration attitude. The information source that was used required interpretation by more experienced users, so that led to more collaboration. The nature of information needed for the project was mostly undocumented and sometimes interpretation was needed, so the designer needed to collaborate with colleagues.

Wang and Strong [32] made a contribution to finding the relationship between the task to be performed and its effect on information search behavior by reviewing most of the papers on search behavior. The study showed that the task characteristics have a direct impact on search behavior. As the complexity of the task increases, searchers tend to spend more time and resources searching. A person's domain knowledge affects the tools and tactics used as they become more complex and diverse. Kim and
Soergel [21] further extended the relation between task and information by proposing independent task characteristics affecting the nature of the information requirements. Bystrom and Hansen [3] proposed a conceptual framework for tasks in information search studies. They addressed the conceptual levels of information-seeking tasks and information search tasks. Information retrieval is defined as a sub-process of information search tasks.

A study on reducing costs by improving problem-solving skills in a plastics manufacturing company showed the effect of the type of a problem on information-gathering behavior to solve that problem. The study included the formal training on the $5 \mathrm{~S}$ problem-solving model: identifying the problem, gathering information, generating alternative solutions, evaluating solutions, and implementing the best solution. After a year of experience, only $25 \%$ of the problems were solved using the sequential pattern. Most of the problems continued to be solved by using a time- and resource-costly cyclical pattern. This was because the nature of complex problems requires more information to identify problems or requires more information to generate alternative solutions [10]. This case illustrates the importance of information and its relative value for the task or problem being treated.

Task characteristics are grouped according to their complexity, their multipath and multisource nature [9]. Tasks at the operational level are characterized by being simple, with usually one step or only a few defined steps to complete. Tasks at the decision-making level are defined by a level of collaboration, information-seeking behavior, iterative nature, novelty, rule using requirements, judgments, and decision-making properties. Strategic tasks are defined by the properties of fuzziness, interrelatedness, and strategic performance requirements.

The concepts of task complexity, path multiplicity, goal multiplicity, amount of information needed for completing a task, task effort, and information-seeking behavior were used in the design of the task-based and information-based constructs in this study.

\subsection{Information characteristics}

Information obviously lies at the heart of information systems. It would be noteworthy to tap into the world of information and seek hints of information quality. Gory and Scott Morton [16] proposed a framework that considered business activities and the information requirements for implementation of management information systems. Their framework consisted of two dimensions: a problem structure dimension and a management activity dimension. Problem structure can be divided into three sub-dimensions: structured, semi-structured, and unstructured. A structured problem can be well-defined in the three phases of problem-solving: intelligence, design, and choice. Some examples are accounts receivable, order entry, and payroll. Semi-structured and unstructured problems do not have a well-defined environment, methodology, and solution spectrum in contrast to structured ones. It is not surprising that most of the managerial decisions fall in the semi-structured and unstructured domains. Management information systems are designed and developed to meet well-structured problems. In the authors' observation, managerial activities require different information characteristics between operational and strategic; and they defined source, scope, level of aggregation, time horizon, currency, required accuracy, and frequency of use as important information characteristics. Information requirements of operational control rely on largely internal sources, the scope is well defined, the level of aggregation is detailed, and accuracy and currency levels are high. On the contrary, information requirements for strategic planning tend to have external sources, the scope is wide, time horizons target the future, and currency and accuracy tend to be not very important [16]. 
DeLone and McLean [11] proposed an Information System (IS) success model. The initial model consists of six major categories; system quality, information quality, use, user satisfaction, individual impact, and organizational impact. The categories in the model are multidimensional and interdependent.

The information quality category of the model included empirical measures. Accuracy, precision, currency, timeliness, reliability, completeness, conciseness, format, relevance, sufficiency, understandability, freedom from bias, relevance to decisions, comparability, quantitativeness, and usefulness of information are suggested in their study. These characteristics of information are mostly used to define the outputs of an information system.

The model has been revisited and improved to include Information quality, system quality, and service quality as driving categories in IS success, and they affect user satisfaction and intention to use and actual use. The last two categories are interdependent and both influence net benefits, which in return affect user satisfaction and intention to use $[12,13]$.

The dimensions of information quality have been defined as relevance, accuracy, timeliness, completeness, coherence, format, accessibility, compatibility, security, and validity [24]. Miller also noted that the real quality aspects of the information are based on the way it is perceived and used by its customer.

Information is the major input in managerial decisions. The quality of the information will determine the success of the given decisions. Sauter [28] described timeliness, sufficiency, level of detail and aggregation, redundancy, understandability, freedom from bias, reliability, decision relevance, cost efficiency, comparability, quantifiability, and appropriateness as dimensions of information required in managerial decision support. Shankaranarayannan and Cai [30] discussed the incorporation of contextual concerns to assess information quality. They proposed a methodology to measure completeness of information. The quality of information is not straightforward for all cases. A certain bit of information might be very useful in one case whereas it might be inadequate for another depending on the context. Data accuracy and completeness are prescribed as important dimensions of information quality [25]. The result of relational aggregate functions as Count, Sum, Average, Max and Min may result in errors leading to wrong managerial decisions. Thus, the system should provide a means either for the correction or for indicators of error probability. Schulte and Gruner [29] argued the effectiveness of organizational hierarchical designs based on decentralized information processing for better decision cost, decision delay, and decision quality. All these dimensions refer to information cost, information timeliness, and information quality, respectively.

The study of information quality has been a concern in Management of Information Systems (MIS) research for years. The Assistance in Maintenance and Quality (AIMQ) methodology foresees information quality under intrinsic, contextual, representational, and accessibility categories [23]. The methodology consists of three basic components: a product, service, and information quality model; an information quality assessment (IQA) instrument, and finally information gap analysis techniques. The first collects information characteristics into four quadrants of sound, dependable, useful, and usable information. The IQA instrument consists of several questions for each dimension. IQ gap analysis tries to find out the gaps in each quadrant.

The concept of "fitness for use" emphasizes the data consumers' point of view. Users' views about data quality are grouped into major aspects to be considered in data quality: intrinsic, contextual, representational, and accessibility concerns [32]. Believability, accuracy, objectivity, and reputation are categorized as intrinsic data quality (IDQ) characteristics. IDQ is used to define inherent characteristics of information. Contextual data quality (CDQ) is about information characteristics that vary based on time, task, place, and person. Value-added, relevancy, timeliness, completeness, and appropriate amount of data are grouped under CDQ. On the contrary, the last two aspects emphasize system characteristics. Interpretability, ease of understanding, representational consistency, and concise representation are the characteristics under representational data quality (RDQ). The accessibility data quality aspect relates to accessibility and access security issues.

The information dimensions are critical in interoperable or integrated IS implementations. The motivation of system users toward IS use is determined by the information dimensions facilitating job execution and fitting the job to be performed. Sharing critical information facilitates and improves peer support, whereas the level of detail and compatibility between different data improves organizational performance [8].

The concepts of reliability, availability, currency, pattern of information change, consistency, accuracy, data richness, scope, level of information, and relevance of information were used in the design of the information-based constructs.

\section{Methodology}

This study included multiple phases. Literature review resulted in a taxonomy [9] which was then filtered through a qualitative step with an expert focus group. A pilot study was conducted to fine tune the research instrument. Finally field survey concluded the study.

\subsection{Expert focus group study}

The expert focus group study was performed to get experts' comments on characteristics of information and business activities. The feedback was used to further refine the final characteristics under research.

Ten experts participated in this study. The participants mostly were experts and practitioners in their fields. Four of them had more than 15 years' experience, four of them had more than 10 years' experience, and the rest had more than 5 years' experience.

The questionnaire was prepared in Excel and distributed via email to the participants. The terminology of characteristics was given both in English and Turkish. The aim of giving constructs in two languages was to clarify the meaning of terminology in the native language of the experts. The list also contained an explanation of the construct. Experts were asked to select the most important 20 characteristics out of 54. Experts were asked to make free comments on any of the items.

\subsection{Pilot study}

A pilot study was conducted to improve the quality of the final experimental study. It was formed of two parts: and observed experiment and a Web-based pilot.

The observed experiment had three participants who were chosen from experienced professionals. They were observed one by one. Participants were asked to make verbal comments about the questionnaire. Those comments were used to improve the expression power of the questionnaire. The final Web-based questionnaire was prepared on that feedback.

Eleven participants were invited via an email invitation, which included a link to the Web site. The responses from the pilot were used as input for a data set for reliability and factor analysis using SPSS (Statistical Package for the Social Sciences). The results of the reliability analysis were used to reduce the number of irrelevant items in the questionnaire. The factor analyses were used to reduce the items per factor. Due to the small size of the experiment group, 
only clear-cut results were taken.

\subsection{Experimental study}

The final experimental study was conducted to research the propositions of the framework. The target audience was people with some work experience and a profound use of information technologies in a business environment. The questionnaire was send to 237 people and to 14 corporations via email invitation. There were 148 responses in total of which 130 were valid, indicating a $59 \%$ response rate.

\section{Model}

The framework and research hypotheses developed are covered in this section.

\subsection{Task information fit model environment}

The Task Information Fit model is the result of an in-depth literature survey and previous qualitative studies. The major constructs of the model are task, information, system and self-related beliefs about work (self work). The general model is summarized in Fig. 1.

Research hypotheses for the model of the framework are given in Table 1. Finding the relations between the major constructs is one of the main objectives of this research.

- H1: System characteristics have an impact on information characteristics of the model.

- H2: System characteristics have an impact on performance.

- H3: Self work characteristics have an impact on information characteristics of the model.

- H4: Self work characteristics have an impact on performance.

- H5: Self work characteristics have an impact on task characteristics of the model.

- H6: Task characteristics have an impact on information characteristics of the model.

- H7: Information characteristics have an impact on performance.

- H8: Task characteristics have an impact on performance.

\subsection{Task information fit model}

Another model developed during the study is a model based on information characteristics. The relationship between different information characteristics driven by the tasks being defined and
Table 1

Task information fit model hypotheses.

\begin{tabular}{llll}
\hline Hypotheses & Dependant & Independent & Relationship \\
\hline H1 & Information & System & Positive \\
H2 & Performance & System & Positive \\
H3 & Information & Self Work & Positive \\
H4 & Performance & Self Work & Positive \\
H5 & Task & Self Work & Positive \\
H6 & Information & Task & Positive \\
H7 & Performance & Information & Positive \\
H8 & Performance & Task & Positive \\
\hline
\end{tabular}

leading to business performance was the core of this model. Research propositions for the model of the framework are given in Table 2 and Fig. 2.

- Pa: Defined tasks have an impact on relevant information.

- Pb1: Consistency has a positive effect on relevant information under a stable environment by means of information change.

- $\mathrm{Pb} 2$ : Consistency has a negative effect on relevant information in a fast-changing environment.

- Pc: Availability has an impact on currency.

- Pd: Currency has an impact on relevant information.

- Pe: Accuracy has an impact on relevant information.

- Pf: the right level of information has an impact on relevant information.

- Pg: Scope has an impact on relevant information.

- Ph: Relevant information has an impact on performance.

\section{Findings}

\subsection{Findings of the expert focus group study}

In the expert group study, 10 experts replied to the invitation. Table 3 shows the characteristics that were chosen to be important by at least 8 of the experts.

\subsection{Findings of the pilot study}

There were 11 participants in the pilot study. Reliability analysis on a per-construct basis was computed. The results of the analysis were used to eliminate redundant items. Table 4 shows the number of items under each construct after the reduction.

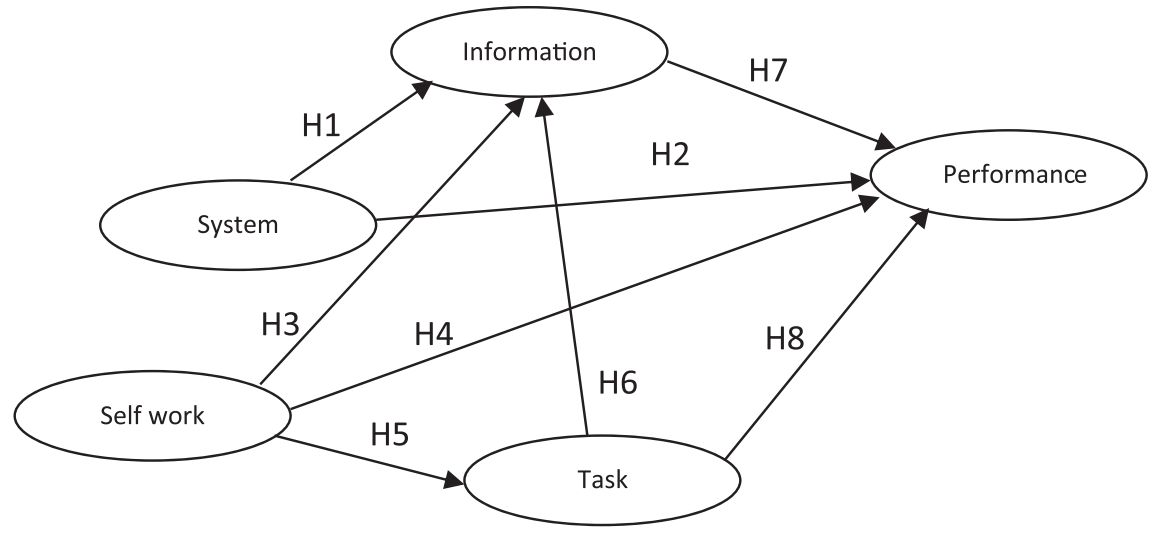

Fig. 1. Task information fit model environment. 
Table 2

Task information fit model propositions.

\begin{tabular}{|c|c|c|c|c|}
\hline Proposition & Dep. Var. & Ind. Var. & Relationship & Condition \\
\hline $\mathrm{Pa}$ & Relevant Info & Task Defined & Positive & \\
\hline $\mathrm{Pb} 1$ & Relevant Info & Consistency & Positive & Stable Environment \\
\hline $\mathrm{Pb} 2$ & Relevant Info & Consistency & Negative & Fast-Changing Environment \\
\hline Pc & Currency & Availability & Positive & \\
\hline Pd & Relevant Info & Currency & Positive & \\
\hline $\mathrm{Pe}$ & Relevant Info & Accuracy & Positive & \\
\hline $\mathrm{Pf}$ & Relevant Info & Right Level & Positive & \\
\hline $\mathrm{Pg}$ & Relevant Info & Scope & Positive & \\
\hline $\mathrm{Ph}$ & Performance & Relevant Info & Positive & \\
\hline
\end{tabular}

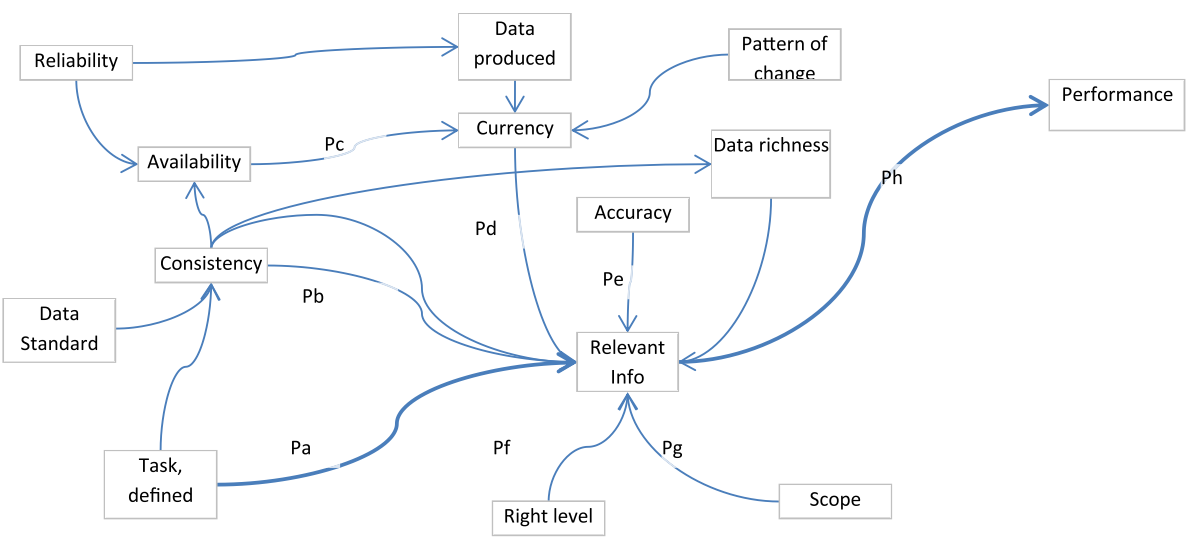

Fig. 2. Task information fit model.

Table 3

Most important characteristics selected by experts.

\begin{tabular}{ll}
\hline Construct & Grade \\
\hline Education & 9 \\
Job experience & 8 \\
Self-efficacy & 8 \\
Current information & 9 \\
Ease of use & 9 \\
Efficiency & 9 \\
Effectiveness & 8 \\
\hline
\end{tabular}

Table 4

Results of the pilot study.

\begin{tabular}{lcc}
\hline Construct & Before & After \\
\hline Self work & 7 & 3 \\
Information & 29 & 19 \\
Task & 19 & 13 \\
System & 11 & 11 \\
Performance & 12 & 12 \\
Total & 87 & 65 \\
\hline
\end{tabular}

\subsection{Profile of the respondents}

Of the respondents, $21 \%$ were female and $79 \%$ were male. Most of the respondents were age 25-30 and 31-40. Most of the participants worked in ICT or finance departments: 53\% of the respondents worked in the finance sector, while $37 \%$ worked in the ICT sector. The detailed profile is given in Table 5 .

The results of the questionnaire were evaluated in terms of reliability and construct validity. Reliability and factor analysis were used to test them. All super constructs were analyzed by means of reliability analysis and the results are presented in Table 6. Super
Table 5

Profile of the respondents.

\begin{tabular}{|c|c|c|c|}
\hline Item & Range & Frequency & Percentage \\
\hline \multirow[t]{2}{*}{ Gender } & Female & 27 & 21 \\
\hline & Male & 103 & 79 \\
\hline \multirow[t]{4}{*}{ Age } & $<25$ & 20 & 15 \\
\hline & $25-30$ & 65 & 50 \\
\hline & $31-40$ & 39 & 30 \\
\hline & $>40$ & 6 & 5 \\
\hline \multirow[t]{6}{*}{ Education } & Basic Education & 1 & 1 \\
\hline & High School & 3 & 2 \\
\hline & Higher Education & 3 & 2 \\
\hline & University Student & 8 & 6 \\
\hline & Bachelor's Degree & 74 & 57 \\
\hline & Graduate Degree & 41 & 32 \\
\hline \multirow[t]{4}{*}{ Department } & Accounting & 1 & 1 \\
\hline & Finance & 35 & 27 \\
\hline & IT & 58 & 45 \\
\hline & Other & 36 & 28 \\
\hline \multirow[t]{6}{*}{ Position } & Accounting, Finance Specialist & 12 & 9 \\
\hline & Accounting, Finance Manager & 2 & 2 \\
\hline & Software Developer & 27 & 21 \\
\hline & Software Project Manager & 11 & 8 \\
\hline & Analyst & 9 & 7 \\
\hline & Other & 69 & 53 \\
\hline \multirow[t]{8}{*}{ Sector } & Finance & 69 & 53 \\
\hline & ICT & 48 & 37 \\
\hline & Education and Consulting & 4 & 3 \\
\hline & Construction & 3 & 2 \\
\hline & Production & 2 & 2 \\
\hline & Health & 1 & 1 \\
\hline & Tourism and Catering & 3 & 2 \\
\hline & Other & & \\
\hline \multirow[t]{5}{*}{ Work experience } & $<1$ & 14 & 11 \\
\hline & $2-3$ & 37 & 28 \\
\hline & $4-5$ & 26 & 20 \\
\hline & $6-10$ & 37 & 28 \\
\hline & $>10$ & 16 & 12 \\
\hline
\end{tabular}


Table 6

Reliability of the major constructs.

\begin{tabular}{lcl}
\hline Major construct & Items & Cronbach's alpha \\
\hline Self work & 3 & 0.70 \\
Task & 13 & 0.74 \\
Information & 19 & 0.88 \\
System & 12 & 0.88 \\
Performance & 12 & 0.96 \\
\hline
\end{tabular}

constructs have Cronbach's alphas of values 0.70 and more. These results indicate high internal consistency of the constructs.

Other multi-item variables' reliability was also analyzed. These results include values with lower Cronbach's alpha values. The results are summarized in Table 7. Task uncertainty and ease of use have a medium level of internal consistency. On the contrary, defined task, task sophistication, information validity, system interoperability, system flexibility, and user interface have a rather higher level of internal consistencies.

\subsection{Descriptive statistics}

The results of the descriptive statistics showed participants' intention to value the most personal attitude about their tasks. They think that their job is highly sophisticated and complex. The most outstanding characteristics of information are information scope and information validity. Defined tasks, system ease of use, information, and system flexibility are treated almost equally by users. Participants do not consider system user interface to be highly critical for their jobs. Descriptive statistics of summated constructs are listed in Table 8.

\subsection{ANOVA statistics}

ANOVA analyses were made based on demographic variables as gender, age, and job experience. The age group of lower than 25 and higher than 40 considered information provided by the information systems to be reliable. Again, the same groups considered that systems are easy to use. The age groups of $26-30$ and $31-40$ considered both to be less important. Results are summarized in Table 9.

Significant ANOVA results based on work experience are summarized in Table 10. All of the respondent groups think that their job requires a high level of collaboration with peers. The rate of perception that the information provided can hold multiple meanings increases with work experience. Another explanation could be that more years of work experience bring more responsibility and require higher level decision-making.

Significant ANOVA results based on job positions are summarized in Table 11.

The codes of 1, 2, 3, 4, 5, and 6 correspond to accounting-finance specialist, accounting-finance manager, software developer, software project manager, analyst, and other respectively. Near all of

Table 7

Reliability of multi-item constructs.

\begin{tabular}{lll}
\hline Multi-item construct & Items & Cronbach's alpha \\
\hline Task defined & 3 & 0.79 \\
Task sophistication & 2 & 0.71 \\
Task uncertainty & 2 & 0.59 \\
Information validity & 2 & 0.75 \\
System interoperability & 2 & 0.94 \\
System flexibility & 2 & 0.79 \\
System user interface & 2 & 0.83 \\
System ease of use & 2 & 0.66 \\
\hline
\end{tabular}

Table 8

Descriptive statistics of the questionnaire.

\begin{tabular}{lllllll}
\hline Construct & Mean & S.D. & Median & Mode & Min & Max \\
\hline Self work & 4.31 & 0.79 & 4.67 & 5 & 1.33 & 5 \\
Task sophistication & 4.27 & 0.84 & 4.5 & 5 & 1 & 5 \\
Task general & 3.89 & 0.53 & 3.92 & 3.77 & 2.08 & 5 \\
Task complexity & 3.85 & 0.87 & 4 & 3 & 1 & 5 \\
Information scope & 3.7 & 0.77 & 3.5 & 3 & 1 & 5 \\
Information validity & 3.69 & 0.94 & 3.5 & 4 & 1 & 5 \\
Task uncertainty & 3.68 & 0.97 & 3.75 & 3.5 & 1 & 5 \\
Performance & 3.66 & 0.96 & 3.67 & 5 & 1 & 5 \\
Task defined & 3.59 & 1.01 & 3.67 & 5 & 1 & 5 \\
System EoU & 3.58 & 0.93 & 3.5 & 4 & 1 & 5 \\
Information general & 3.56 & 0.63 & 3.63 & 3.42 & 1.26 & 4.8 \\
System flexibility & 3.54 & 0.97 & 3.5 & 3 & 1 & 5 \\
Information content & 3.44 & 0.9 & 3.5 & 3.5 & 1 & 5 \\
System & 3.42 & 0.74 & 3.43 & 3.29 & 1.57 & 5 \\
System UI & 1.83 & 0.54 & 2 & 2 & 0.5 & 2.5 \\
\hline
\end{tabular}

Table 9

Significant ANOVA results for age.

\begin{tabular}{lllllll}
\hline Construct & $<25$ & $26-30$ & $30-40$ & $>40$ & F & Sig. \\
\hline Information content 1 & 4.45 & 3.74 & 3.77 & 4.67 & 3.39 & 0.020 \\
Ease of use 2 & 3.89 & 3.26 & 2.67 & 4.0 & 3.02 & 0.037 \\
\hline
\end{tabular}

Table 10

Significant ANOVA results for work experience.

\begin{tabular}{llllllll}
\hline Construct & $<1$ & $1-3$ & $4-5$ & $6-10$ & $>10$ & F & Sig. \\
\hline Collaborative task & 4.50 & 4.16 & 4.27 & 4.51 & 4.94 & 2.58 & 0.041 \\
Information content 2 & 2.13 & 2.92 & 3.05 & 3.27 & 3.43 & 2.65 & 0.036 \\
\hline
\end{tabular}

Table 11

Significant ANOVA results for job positions.

\begin{tabular}{lllllllll}
\hline Construct & 1 & 2 & 3 & 4 & 5 & 6 & F & Sig. \\
\hline Task uncertainty 2 & 3.75 & 4.00 & 4.00 & 4.09 & 4.22 & 4.12 & 2.34 & 0.045 \\
Information complete & 3.75 & 4.50 & 2.52 & 3.09 & 3.00 & 3.22 & 2.58 & 0.030 \\
Detail level & 4.00 & 4.50 & 3.07 & 3.45 & 3.22 & 3.70 & 2.43 & 0.038 \\
Information validity 1 & 4.08 & 4.50 & 3.41 & 3.27 & 3.33 & 3.93 & 2.32 & 0.047 \\
User interface 2 & 3.92 & 4.50 & 4.04 & 4.00 & 3.33 & 3.22 & 3.19 & 0.010 \\
Performance 2 & 4.25 & 4.50 & 3.81 & 4.18 & 2.78 & 3.96 & 3.04 & 0.013 \\
Performance 3 & 4.17 & 4.50 & 3.67 & 4.27 & 2.67 & 3.74 & 2.34 & 0.045 \\
Performance 5 & 4.17 & 4.50 & 3.63 & 4.27 & 2.67 & 3.70 & 2.79 & 0.020 \\
Performance 12 & 4.00 & 4.50 & 3.15 & 4.27 & 2.67 & 3.62 & 2.99 & 0.014 \\
\hline
\end{tabular}

the participants stated that, their job tasks can change due to work requirements. This was slightly higher for analysts and software project managers, which is natural for their environment. Finance sector workers stated that information is mostly complete in their business environment; nonetheless, this is not the case with software business. Again that is the observation for the level of information detail and information validity. Analysts find that user interfaces of their systems are not as user-friendly as they should be. Financial specialists and software project managers think that systems in use have a positive effect on their job performance over all. Software developers think that systems are fairly good. On the contrary, analysts think that systems have neither positive nor negative effects on their business performance.

\subsection{Analysis of the framework}

Linear regression analyses were used to measure proposed interrelations between dependent and independent constructs on the TIF model environment. The results are summarized in Fig. 3. 


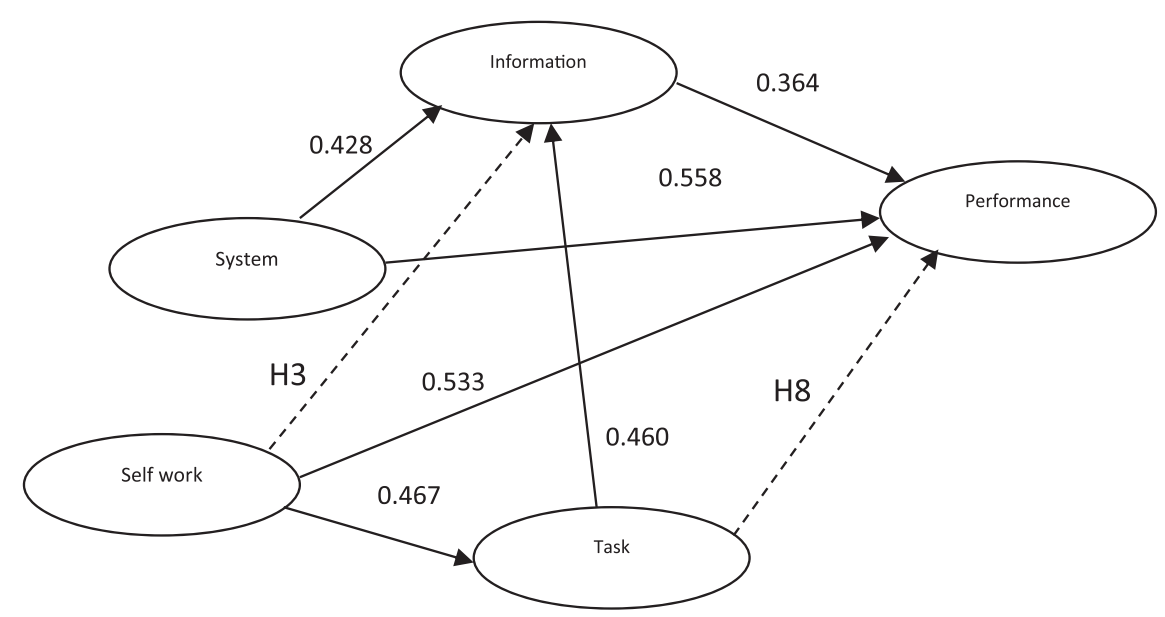

Fig. 3. Results of the TIF model environment.

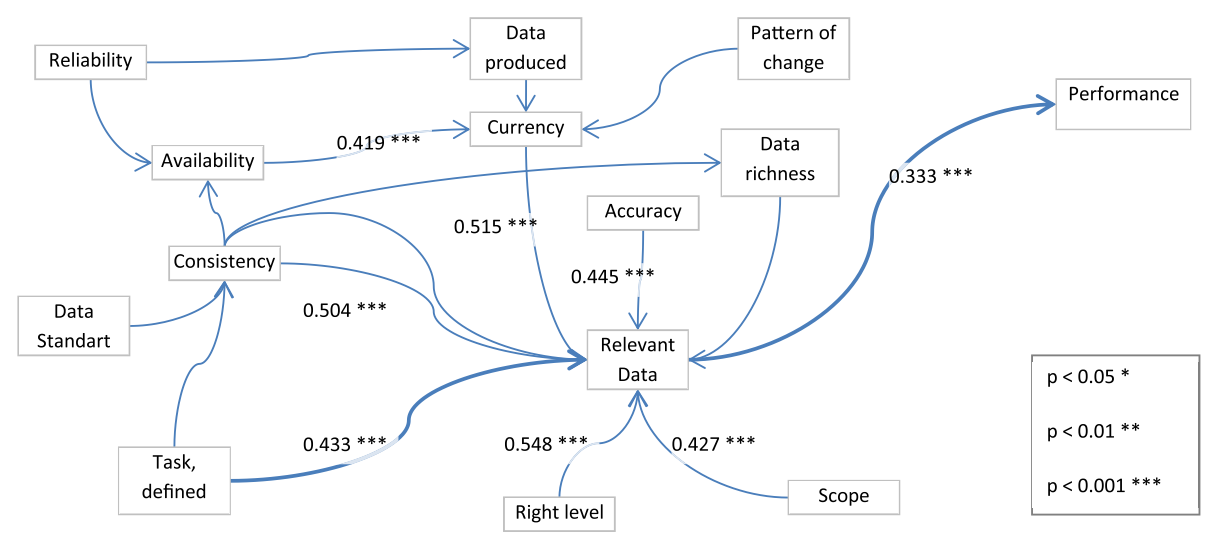

Fig. 4. Results of the TIF model.

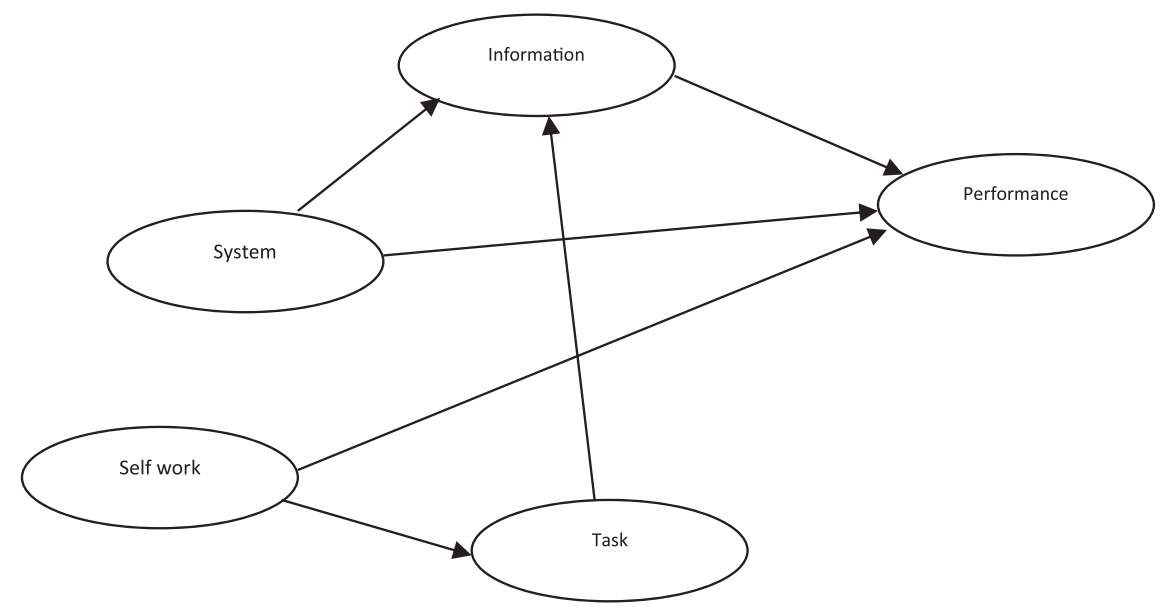

Fig. 5. Results of the TIF model environment.

The hypotheses $\mathrm{H} 3$ and $\mathrm{H} 8$ were not supported by the findings. All of the other six hypothesizes had a significance level smaller than 0.001 , which indicates that they are highly significant. According to the results, task and system characteristics have similar effects on information. Self work and system have a higher impact on performance than information. An interesting finding is that users do not directly correlate performance and task characteristics.
Results of the TIF model were derived from item correlation statistics. The results are shown in Fig. 4. The model was built to explain the chain of task, information, and performance. Correlation results support the model. All of the supported propositions are significant with the exception of proposition $\mathrm{Pb} 2$, for which there was no evidence. The correlation between items in the model is one of the unique contributions of the study. The internal 


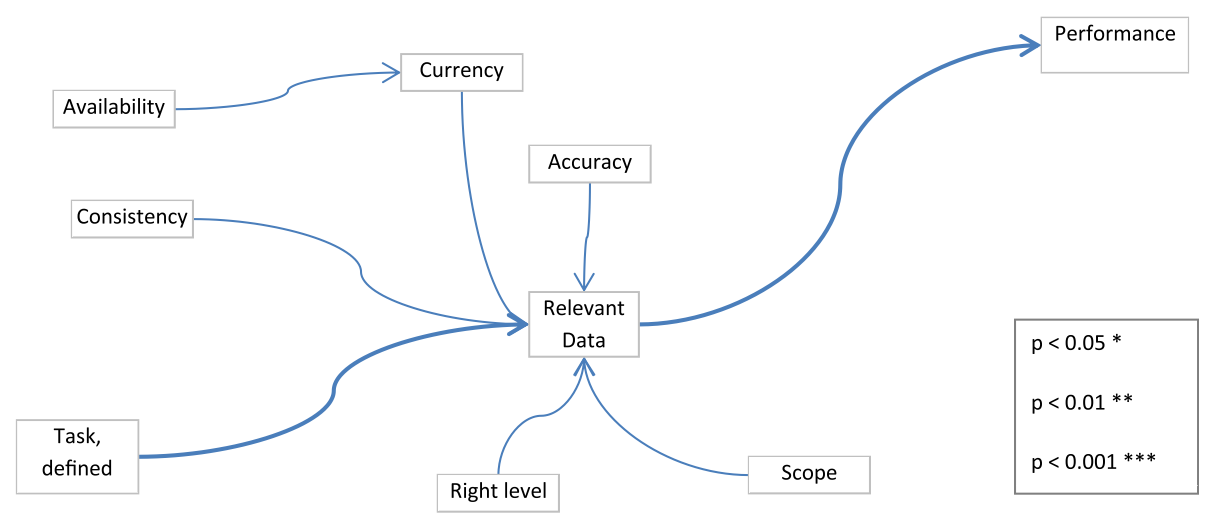

Fig. 6. Results of the TIF model.

relations between information characteristics, the flow from task to information characteristics, and the relation between relevant information characteristic to performance are noteworthy.

\section{Conclusion}

The goal of the study was to develop a model of task information fit (TIF). Results indicate that the tool has been successful and models the underlying structure between system characteristics, task characteristics, information characteristics, and their impact on perceived business success to some degree. A reduced TIF model was targeted to discover the relation between task characteristics, information characteristics, and their effect on business performance on a per-item basis. The correlations between the items supported the proposed relations. One of the unique contributions of this study is to reveal the underlying relations between task and information characteristics.

Figs. 5 and 6 represent the final models summarizing most important elements.

The frameworks proposed in this research can be used as a basis for further development of a more comprehensive framework. Dimensions from social, psychological, and organizational domains can be added to build a more complete model. The relations within the model on a per-item basis can be examined.

\section{References}

[1] A.D. Amar, Motivating knowledge workers to innovate: a model integrating motivation dynamics and antecedents, Eur. J. Innov. Manag. 7 (2) (2004) 89-101.

[2] D. Buchanan, The Development of Job Design Theories and Techniques, Praeger Publishers, New York, 1979.

[3] K. Byström, P. Hansen, Conceptual framework for tasks in information studies, J. Am. Soc. Inf. Sci. Technol. 50 (10) (2005) 1050-1061.

[4] K. Byström, K. Järvelin, Task complexity affects information seeking and use, Inf. Process. Manag. 31 (2) (1995) 191-213.

[5] D. Campbell, Task complexity: a review and analysis, Acad. Manag. Rev. 13 (1988) 40-52.

[6] M.A. Campion, Interdisciplinary approaches to job design: a constructive replication with extensions, J. Appl. Psychol. 73 (3) (1988) 467-481.

[7] M.A. Campion, P.W. Thayer, Job design: approaches outcomes, and trade-offs, Organ. Dyn. 15 (3) (1987) 66-79.

[8] S. Cayir, A.N. Basoglu, Information technology interoperability awareness: a taxonomy model based on information requirements and business needs, in: PICMET 2008, Portland International Conference on Management of Engineering \& Technology, July 2008, pp. 846-855.

[9] S. Cayir, A.N. Basoglu, T.U. Daim, Users and information technology: analysis of task information fit model, Int. J. Inf. Decis. Sci. 2 (4) (2010) 401-406.
[10] S.S. Chakravorty, D.N. Hales, J.I. Herbert, How problem-solving really works, Int. J. Data Anal. Tech. Strateg. 1 (1) (2008) 44-59.

[11] W.H. DeLone, E.R. McLean, Information systems success: the quest for the dependent variable, Inf. Syst. Res. 3 (1) (1992) 60-95.

[12] W.H. DeLone, E.R. McLean, Information systems success revisited, in: Proceedings of the 35th Hawaii International Conference on System Sciences (HICSS 02). Big Island, Hawaii, 2002, pp. 238-249.

[13] W.H. DeLone, E.R. McLean, The DeLone and McLean, model of information systems success: a ten-year update, J. Manag. Inf. Syst. 19 (4) (2003) 9-30.

[14] R. Fidel, A.M. Pejtersen, B. Cleal, H. Bruce, A multi-dimensional approach to the study of human-information interaction: a case study of collaborative information retrieval, J. Am. Soc. Inf. Sci. Technol. 55 (11) (2004) 939-953.

[15] P. Garg, P. Rastogi, New model of job design: motivating employees' performance, J. Manag. Dev. 25 (6) (2006) 572-587.

[16] G.A. Gorry, M.S. Scott-Morton, A framework for management information systems, Sloan Manag. Rev. 13 (1) (1971) 55-70.

[17] J. Hackman, G. Oldham, Motivation through the design of work: test of a theory, Organ. Behav. Hum. Perform. 15 (1976) 250-279.

[18] J.R. Hackman, R.G. Oldham, R. Janson, K. Purdy, A new strategy for job enrichment, Calif. Manag. Rev. 17 (4) (1975) 55-71.

[19] D. Holman, C. Clegg, P. Waterson, Navigating the territory of job design, Appl. Ergon. 33 (3) (2002) 197-205.

[20] D. Jonassen, Toward a design theory of problem solving, Educ. Technol. Res. Dev. 48 (2000) 63-85.

[21] S. Kim, D. Soergel, Selecting and measuring task characteristics as independent variables, in: Proceedings of the 68th Annual Meeting of the American Society for Information Science and Technology, vol. 42, No. 1, 2005.

[22] K. Lauche, Job design for good design practice, Des. Stud. 26 (2) (March 2005) 191-213. March 2005.

[23] H.L. Lee, K.C. So, C.S. Tang, The value of information sharing in a two-level supply chain, Manag. Sci. 46 (5) (2000) 626-643.

[24] H. Miller, The multiple dimensions of information quality, Inf. Syst. Manag. 13 (2) (1996) 79-83.

[25] A. Parssian, Managerial decision support with knowledge of accuracy and completeness of the relational aggregate functions, Decis. Support Syst. 42 (3) (2006) 1494-1502.

[26] J. Rasmussen, A.M. Pejtersen, K. Schmidt, Taxonomy for Cognitive Work Analysis, Citeseer, 1990.

[27] J. Rasmussen, A framework for cognitive task analysis in systems design, in: Proceedings of the NATO Advanced Study Institute on Intelligent Decision Support on Intelligent Decision Support in Process Environments, 1986, pp. $175-196$.

[28] V. Sauter, "Data Components" in Decision Support Systems, John Wiley, New York, 1997, pp. 47-99.

[29] E. Schulte, H.P. Grüner, Speed and quality of collective decision making: imperfect information processing, J. Econ. Theory 134 (1) (2007) 138-154.

[30] G. Shankaranarayanan, Y. Cai, Supporting data quality management in decision-making, Decis. Support Syst. 42 (2006) 302-331.

[31] U.D. Sitter, J.F.D. Hertog, B. Dankbaar, From complex organizations with simple jobs to simple organizations with complex jobs, Hum. Relat. 50 (5) (1997) 497-534.

[32] R.Y. Wang, D.M. Strong, Beyond accuracy: what data quality means to data consumers, J. Manag. Inf. Syst. 12 (3) (1996) 33.

[33] M. Zapf, U. Lindheimer, A. Heinzl, The myth of accelerating business processes through parallel job designs, Inf. Syst. E Bus. Manag. 5 (2) (2007) 117-137. 